\title{
Media Coverage of Youth Suicides and Its Impact on Paediatric Mental Health Emergency Department Presentations
}

\section{Couverture médiatique du suicide chez les jeunes et répercussions sur les visites aux services des urgences en santé mentale pédiatrique}

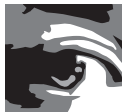

STEPHANIE L. LEON, BSC

PhD Student in Clinical Psychology

Children's Hospital of Eastern Ontario Research Institute

Ottawa, ON

PAULA CLOUTIER, MA

Research Associate

Children's Hospital of Eastern Ontario Research Institute Ottawa, ON

MARC-ANDRÉ BÉLAIR, BSSC

$M S c$ Candidate in Epidemiology

Children's Hospital of Eastern Ontario Research Institute Ottawa, ON

MARIO CAPPELLI, PHD, CPSYCH

Director of Mental Health Research

Children's Hospital of Eastern Ontario Research Institute

Ottawa, ON 


\begin{abstract}
Background: To examine mental health (MH) presentations to the emergency department (ED) of a paediatric hospital following two highly publicized local teen suicides. Methods: Youths aged 12-18 years with a MH chief complaint and/or diagnosis were included. Differences in frequencies were analyzed using chi-square tests, and relative risks were evaluated using generalized linear modelling.

Results: Significant increases in the number of ED presentations were found within the months of the publicized suicides compared to the same months of previous years. No differences were found in symptom acuity, suicidal status and psychiatric hospitalization rates. Significant increases were found in relative risk of presenting to the ED 28 and 90 days post both publicized suicides.

Conclusions: Results suggest there was an association between highly publicized suicides and an increase in the number of $\mathrm{MH}$ presentations to the local paediatric ED. Considerations of medias potentially positive role in $\mathrm{MH}$ awareness are needed.
\end{abstract}

\title{
Résumé
}

Contexte : Examiner les visites pour raison de santé mentale aux services des urgences d'un hôpital pédiatrique suite à deux suicides d'adolescents fortement couverts par les médias locaux. Méthode : Les jeunes de 12 à 18 ans avec un motif de consultation et/ou un diagnostique lié à la santé mentale ont été inclus dans cette étude. Les différences dans la fréquence ont été analysées au moyen du test de chi carré et les risques relatifs ont été évalués par modélisation linéaire généralisée.

Résultats : Nous avons observé un accroissement significatif des visites aux services des urgences dans les deux mois qui ont suivi l'annonce des suicides, comparativement aux mêmes mois de l'année précédente. Nous navons pas observé de différences dans la gravité des symptômes, le statut suicidaire et les taux d'hospitalisation pour raisons psychiatriques. Nous avons observé un accroissement significatif du risque relatif de se présenter aux services des urgences de 28 à 90 jours après l'annonce des suicides.

Conclusions: Les résultats font voir qu'il y a un lien entre les suicides hautement médiatisés et un accroissement du nombre de visites pour des raisons de santé mentale aux services des urgences d'un hôpital pédiatrique local. Il est nécessaire de se pencher sur le rôle potentiellement positif des médias dans la prise de conscience sur la santé mentale.

\section{Wo recent youth suicides in the Ottawa Region garnered tremendous media attention and personalized the risk associated with paediatric mental ill- ness for all community members. The first was the death of Daron Richardson, the} daughter of Ottawa Senators assistant coach and longtime National Hockey League (NHL) player Luke Richardson, on November 12, 2010. Immediately following her death, Daron's parents held a press conference explaining her suicide. Subsequently, many friends, her own 


\section{Media Coverage of Youth Suicides and Its Impact on Paediatric Mental Health}

Emergency Department Presentations

hockey teammates and family members were interviewed and her memorial received extensive media coverage. In January 2011, attention to youth mental health (MH) and suicide was further augmented as school friends launched the Do It for Daron challenge, which became the DIFD Foundation. Today, the DIFD Foundation has spread beyond the Ottawa region, and many organizations (including the NHL) continue to promote the awareness of youth $\mathrm{MH}$ and suicide.

On October 14, 2011, Jamie Hubley, the son of Ottawa city councillor Allan Hubley, committed suicide. His death also received extensive media coverage and his parents openly discussed his suicide with the media. Unlike Daron, who did not have a history of mental illness and whose suicide did not seem to have any prior signs, Jamie was diagnosed and being treated for depression. In his blog, Jamie acknowledged his distress as a result of repeated peer bullying for being gay and that he often contemplated suicide.

\section{Suicide and the Media}

Many studies have looked at the effect of media coverage on suicide rate in the general population (Siask and Värni 2012). Two phenomena are used to describe the association between suicidal behaviour and media exposure: the Werther effect (Gould 2001) and the Papageno effect (Niederkrotenhaler et al. 2010). The Werther effect refers to the positive correlation between media exposure of a suicide event and subsequent suicidal behaviour in the population (Gould 2001). When a suicide event occurs, a dose-response relationship is evident such that suicides increase in proportion to media attention (Gould 2003). Suicide clusters, or imitative suicides, are more frequent in teens and young adults, and suicide risk increases with the number of shared characteristics between the victims (age, gender, peers and family members) and the popularity of the suicide victim (Gould 2001). Canada, along with numerous countries, has imposed news reporting guidelines to decrease the potentially negative effect of media attention surrounding suicides (Gould 2001, 2003). In Canada, the guidelines urge the media to avoid: perpetrating the myth that suicide is unexplainable, identification with the victim through the use of pictures, descriptions of method and location, front-page coverage and sensational headlines (Nepon et al. 2008).

Conversely, the Papageno effect occurs when the media has a suicide-preventing influence (Siask and Värni 2012). For example, Kurt Cobain's (lead singer and guitarist of the Nirvana music group) suicide did not yield the expected Werther effect (Jobes et al. 2006). On the contrary, the number of suicides one week following his death decreased compared to the same week in the year prior and the year following (Jobes et al. 2006). Some have hypothesized that imitative suicides were not observed following the event due to his wife's reaction, because his suicide was not romanticized or glorified in the media and because crisis centre/ community outreach interventions were put in place immediately in many communities (Gould 2001; Jobes et al. 2006). Newspaper blackout, reductions in the quantity of reporting and changes in the quality of media reporting have also shown a protective effect of media coverage and, in some cases, a subsequent short-term decrease in suicides (Siask and Värni 2012). 


\section{Gaps in Current Knowledge}

Although looking at the effect of media coverage of suicides is not new, to our knowledge no studies have looked at its effect on rates of emergency department (ED) MH presentations. Also, little is known about the effects of non-celebrity suicides and, as such events are more common than celebrity suicides, they are important to investigate in the hope of developing preventive strategies (Yang et al. 2013). Furthermore, the potential role of media coverage of mental illness in increasing $\mathrm{MH}$ awareness has yet to be determined. A study tested the effect of a host of media on $\mathrm{MH}$ awareness with relatively good results (Wright et al. 2006). However, more evidence is needed to determine the effectiveness of media-based MH awareness campaigns and what effect it may have on presentations to the ED. Understanding these influences is important because $\mathrm{MH}$ literacy is crucial in the promotion of early detection and treatment of $\mathrm{MH}$ problems (Wright et al. 2006).

The goal of this study was to examine MH presentations to the ED of the local paediatric hospital where the two publicized suicides took place and to determine if ED presentations increased following the extensive media coverage of Daron Richardson's and Jamie Hubley's suicides.

\section{Methods}

We used data from the Children's Hospital of Eastern Ontario (CHEO) ED, which uses the National Ambulatory Care Reporting System (NACRS), to verify the influence of the two youth suicides in the Ottawa region on paediatric MH ED presentations. The NACRS provides hospitals with a standard data collection and reporting tool to capture data for ambulatory care visits, including day surgery, ambulatory care clinics and EDs. We selected all youths aged $12-18$ years (mean $=15.6, \mathrm{SD}=1.6)$ who presented to the $\mathrm{ED}$ with a clear chief complaint related to $\mathrm{MH}$ and/or received an $\mathrm{MH}$ diagnosis as a primary diagnosis. We used the International Statistical Classification of Diseases and Related Health Problems Canadian version (Canadian Institute for Health Information 2006) to determine if patients had received a main ambulatory care diagnosis for mental illness (F20-F99, G47, R45, Z63), substance misuse or abuse (F10-F19, T36-T65, Z03) or intentional self-harm (X60-X84).

We also conducted secondary analyses of clinical data collected prospectively from a second database. This database represents a sub-sample of all paediatric $\mathrm{MH}$ presentations at CHEO, and therefore a sub-sample of the regular ED database. The youths in this database were seen by the Regional Psychiatric Emergency Services for Children and Youth, which responds to $\mathrm{MH}$ emergencies in the ED and on an outpatient basis. Only data from youths who were seen by this crisis intervention team in the ED were selected. Again, we selected all youths aged $12-18$ years $($ mean $=15.1, \mathrm{SD}=1.4)$. These data were used to determine if symptom acuity (as measured by the Child and Adolescent Needs and Strengths tool; CANS-MH 3.0; Lyons et al. 2006), suicidal status (No, Ideation or Plan, Gesture, Attempt) and psychiatric hospitalization rates following the ED presentation were different two weeks 
prior to the publicized suicides compared to the two weeks following. These variables are not collected specifically in NACRS databases. Most studies examining the impact of media reporting on suicidal acts have focused on short-term effects, a few days to three or four weeks (Siask and Värni 2012), which is why our analyses focused on 2-week, 4-week and 90-day periods to determine short- and long-term effects.

\section{Measure}

\section{The Child and Adolescent Needs and Strengths Tool (CANS-MH 3.0)}

The CANS-MH 3.0 is a 60 -item assessment tool used to support decision-making during the process of planning services (Lyons et al. 2006). The CANS-MH effectively communicates the severity of youth's needs ( $\mathrm{MH}$ symptoms and behaviours) and strengths through the use of actionable levels: (0) no evidence, (1) watchful waiting/prevention, (2) action required and (3) immediate/intensive action required. A score of 2 or 3 indicates a need for service. Only relevant needs were included for this study: anxiety (symptoms of anxiety in children such as worries and fears); mood (symptoms of depression in children such as depressed mood, sleep disturbances, weight/eating disturbances, loss of motivation, irritability); substance abuse (use of alcohol and illegal drugs, misuse of prescription medications and inhalation of substance for recreational purposes); attention deficit/impulse control (symptoms of attention deficit and hyperactivity disorder and impulse control disorder such as inattention); oppositional behaviour (non-compliance to authority); conduct behaviour (antisocial behaviours like shoplifting, lying, vandalism, cruelty to animals and assault); social behaviour (socially unacceptable behaviour for the culture and community); and, school behaviour (behavioural difficulties at school). The CANS-MH 3.0 has good inter-rater reliability ( 0.73 on average; Lyons et al. 2006) and good concurrent validity (correlations ranging from 0.63 to 0.72 with the Child and Adolescent Functional Assessment Scale; Hodges and Wotring 2000). The CANS-MH was completed by the crisis intervention team in the ED.

\section{Statistics}

Differences in monthly frequencies of ED presentations were analyzed using the chi-square goodness-of-fit test in SPSS version 20.0. Then, data were aggregated into daily number of presentations for the 2,192-day period from April 1, 2006 to December 31, 2012. A Poisson regression generalized linear model (GLM) was conducted using this 2,192-day period to determine whether the 14-, 28- and 90-day periods post event were statistically significantly associated with an elevated risk of ED presentations. All models controlled for time using a quadratic term. The CANS-MH was dichotomized into no action required (actionable levels 0 and1) and action required (actionable levels 2 and 3), and again, differences between weeks were analyzed using chi-square goodness-of-fit test. Similarly, suicidal status was dichotomized into no suicidality and some suicidality (includes ideation, plan, gesture or attempt). 


\section{Results}

The NACRS database indicated that 6,700 youths meeting the study inclusion criteria presented to the ED between January 2007 and March 2012. Sixty-one percent $(n=4,110)$ of these youths were female. Of all presentations, $46.5 \%(n=3,114)$ were first seen by emergency physicians and $31.7 \%(n=2,123)$ were first seen by social workers. The second database indicated that for the same period, 1,386 youths were seen by the crisis intervention team $(62.6 \%$ were female, $\mathrm{n}=867)$.

FIGURE 1. Monthly mental health presentations from January 2007 to March 2012.

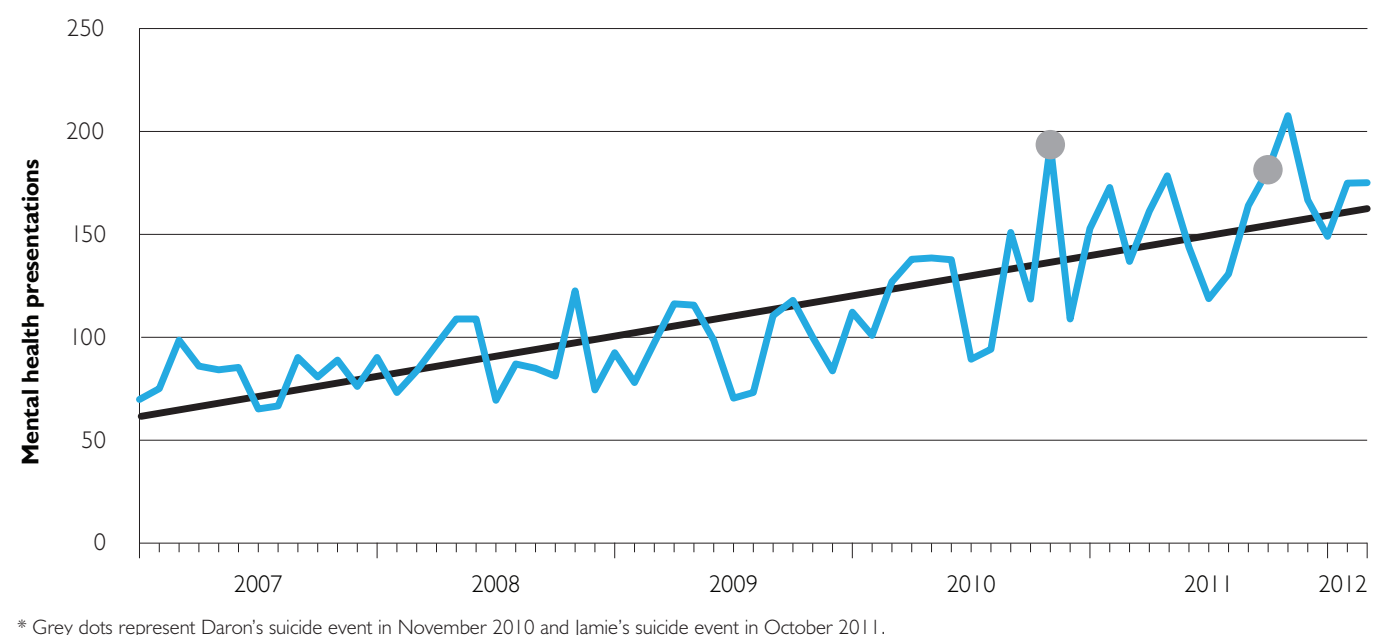

* Grey dots represent Daron's suicide event in November 2010 and Jamie's suicide event in October 20। I.

Year-on-year annual increases in total $\mathrm{MH}$ presentations were evident and ranged from $6 \%$ to $32 \%(2007-2008=10 \% ; 2008-2009=6 \% ; 2009-2010=32 \% ; 2010-2011=30 \%$; 2011-2012 = 7\%). Furthermore, there was a 119\% increase in November 2010 (the month of Daron Richardson's death) compared to the same month in 2009, which is 89 percentage points greater than the overall increase that year. This increase was statistically significant, $\chi^{2}(1, N=292)=30.26, p<0.0001 ; p h i=0.32$. Similarly, but not as dramatic, there was a $59 \%$ increase in October 2011 (the month of Jamie Hubley's death) compared to the same month in 2010, which is 52 percentage points greater than the overall increase that year. This increase was also statistically significant, $\chi^{2}(1, \mathrm{~N}=299)=13.27, p<0.0001 ; p h i=0.21$. As a comparison, in January 2012 another local youth committed suicide. Although his death was reported by the news, it received no further media attention. Following this suicide, there was a 5\% decrease in January 2012 compared to the same month in 2011. This decrease was non-significant, $\chi^{2}(1, \mathrm{~N}=301)=0.03, p=0.86 ; p h i=0.01$. Monthly frequencies of $\mathrm{MH}$ presentations are presented in Figure 1.

Poisson regression modelling was conducted to account for the trend over time. Results are outlined in Table 1. At the 95\% confidence level, all models except for Model 4 (14 days post-Jamie) demonstrated a statistically significant increased risk for ED presentations. 


\section{Media Coverage of Youth Suicides and Its Impact on Paediatric Mental Health}

Emergency Department Presentations

TABLE 1. Risk of presentation to the ED during the 14-, 28- and 90-day periods following Daron's and Jamie's deaths

\begin{tabular}{|l|l|l|l|l|}
\hline Model & Event & Number of days post event & Relative risk (95\% Cl) & $p$-value \\
\hline 1 & Daron & 14 & $1.65(1.32,2.02)$ & $<0.001$ \\
\hline 2 & Daron & 28 & $1.48(1.25,1.73)$ & $<0.001$ \\
\hline 3 & Daron & 90 & $1.16(1.05,1.29)$ & 0.004 \\
\hline 4 & Jamie & 14 & $1.25(0.99,1.56)$ & 0.054 \\
\hline 5 & Jamie & 28 & $1.32(1.12,1.55)$ & $<0.001$ \\
\hline 6 & Jamie & 90 & $1.22(1.10,1.34)$ & $<0.001$ \\
\hline
\end{tabular}

Analyses of the sub-sample of clinical data demonstrated there were no significant differences in symptoms acuity two weeks prior compared to the two weeks following both suicides, except for mood presentations, which increased significantly two weeks following Daron's suicide. Non-significant results were also found for suicidal status and hospitalization rates. Associated chi-squares and p-values are presented in Table 2.

TABLE 2. Comparison of the 2 weeks before and the 2 weeks following the suicide events on symptom acuity, suicidal status and hospitalization rates

\begin{tabular}{|c|c|c|c|c|}
\hline \multirow{2}{*}{$\begin{array}{l}\text { The Child and Adolescent Needs and } \\
\text { Strengths tool (CANS-MH 3.0) }\end{array}$} & \multicolumn{2}{|c|}{$\begin{array}{l}\text { Comparison of the } 2 \text { weeks prior and } \\
\text { the } 2 \text { weeks following Daron's suicide }\end{array}$} & \multicolumn{2}{|c|}{$\begin{array}{l}\text { Comparison of the } 2 \text { weeks prior and } \\
\text { the } 2 \text { weeks following Jamie's suicide }\end{array}$} \\
\hline & $\chi^{2}$ & $p$-value & $\chi^{2}$ & $p$-value \\
\hline Anxiety & 0.47 & 0.493 & 1.04 & 0.307 \\
\hline Mood & 3.9 & $0.048 *$ & 0.18 & 0.674 \\
\hline Substance abuse & 1.14 & 0.285 & 0.09 & 0.763 \\
\hline Attention deficit/impulse control & 0.05 & 0.819 & 0.73 & 0.394 \\
\hline Oppositional behaviour & 1.08 & 0.297 & 2.46 & 0.117 \\
\hline Conduct behaviour & - & - & 0.33 & 0.564 \\
\hline Social behaviour & - & - & 0.67 & 0.414 \\
\hline School behaviour & 0.14 & 0.705 & 0.33 & 0.564 \\
\hline \multicolumn{5}{|l|}{ Other } \\
\hline Suicidal status & 3.11 & 0.078 & 0.08 & 0.780 \\
\hline Psychiatric hospitalization rate & 0.43 & 0.513 & 0.43 & 0.513 \\
\hline
\end{tabular}

Note. There were insufficient data for conduct and social behaviours reported in the weeks around Daron's death to conduct chi-square analyses.

Chi-square analyses of the ratios of males-to-females and the age-at-time-of-presentation were also not found to be significant when comparing the two weeks before and the two weeks following both suicide events $(p>0.05)$. 


\section{Discussion}

$\mathrm{MH}$ presentations to the local paediatric hospital have increased over the past few years, and it appears that extensive media coverage of youth suicides is related to short-and long-term increases in ED presentations. Jamie's suicide did not appear to have had as much of an immediate impact as Daron's on ED presentations. One possible explanation may be differences in media speculation around the underlying causes of each tragedy. In Daron's case, there was a much stronger emphasis on mental illness, while in Jamie's case, the emphasis was put on bullying and the struggles gay teens face every day. Furthermore, the relatively immediate impact of Daron's suicide on ED presentations is in contrast to Yang et al. (2013), who found there was a month-long lag for the effect of reported suicide to be evident in the case of non-celebrity suicides. However, it could be argued that Daron, as the daughter of the Ottawa Senators assistant coach, was more of a "celebrity" than the average youth because of her relationship to the local NHL team. Although we cannot claim a causal relationship, suicides that received media coverage seem to be linked to a greater number of $\mathrm{MH}$ presentations to the local paediatric hospital.

Our results demonstrated no significant clinical differences (symptoms acuity, suicidal status, hospitalization rates) in presentation during the two weeks following both suicides compared to the two weeks before, except for acuity of mood symptoms, which barely reached significance. Interestingly, a recent Korean study that looked specifically at suicide attempts uncovered no significant difference between the number of suicide attempts before and after a celebrity suicide (Kim et al. 2013). The finding that clinical severity of ED presentation was not affected in this study is important because it means that a greater number of youths with $\mathrm{MH}$ problems sought services; youths who may not have sought services otherwise. These results might suggest that the extensive media attention surrounding Daron and Jamie's suicides sensitized the community to $\mathrm{MH}$ issues - possibly through parental identification of youth at risk - and increased help-seeking behaviours for all youths and their families, enabling more youths to receive needed services. In fact, a similar study examining the widespread media coverage of actress Natasha Richardson's fatal head injury also found an increase in ED presentations for head trauma (Richardson et al. 2011). This increase was most pronounced in the paediatric population, which supports the possibility that increased presentations might be driven by parental concerns. Ideally, future studies would directly measure the motivations and expectations of the youth and parents as they present to the ED to determine if presentations increased because of the heightened awareness of MH issues (Cloutier et al., 2010).

On the other hand, increases in ED presentations augment the demands on our already overburdened Canadian EDs (Grupp-Phelan et al. 2007; Mahajan et al. 2009; Newton et al. 2009). Considering that the youths who presented in the weeks following the suicides were comparable in their symptom severity and suicidal status, and knowing that there had been an increase in non-urgent presentations (Sills and Bland, 2002; Edelsohn et al. 2003), some of these youths might have been better served through community resources. As the response to Kurt Cobain's suicide demonstrates, outreach programs in charge of communicating the 


\section{Media Coverage of Youth Suicides and Its Impact on Paediatric Mental Health}

Emergency Department Presentations

different types of services available to youths and directing youths to the most appropriate services, whether in the ED or community-based, might be the most appropriate response to suicide events (Jobes et al. 2006; Richardson et al. 2011). Therefore, early identification, while essential, has to be matched by equivalent improvements in the MH healthcare system.

Although this study focused on specific suicides that occurred within the Ottawa region, the implication of the findings can be applied more broadly. Indeed, this study sheds some light on whether the extensive media coverage of non-celebrity teen suicides yields a Werther or Papageno effect. If increased ED presentations are truly reflecting greater awareness of $\mathrm{MH}$ issues, it could be evidence for the positive role of responsible media coverage and therefore a Papageno effect.

\section{Limitations}

Although CHEO uses the NACRS, we cannot determine the accuracy of the reported chief complaints and diagnostics. However, this has likely led to an underreporting rather than an overreporting of $\mathrm{MH}$ presentations (Yu et al. 2010). Although we have taken care to include all youth with a clear chief complaint related to $\mathrm{MH}$ and/or received an $\mathrm{MH}$ diagnosis as a primary diagnosis, we were conservative in our inclusion criteria. Therefore, the number of youth with $\mathrm{MH}$ problems might have been underestimated because of imprecise chief complaints or differences in coding. Another limitation is that symptom acuity, suicidal status and hospitalization rates were only available for a sub-sample of youth. It may also be the case that higher rates of ED visits are due to events, circumstances or factors other than the two suicide events. For example, it was found that, on average, rates of $\mathrm{MH}$ presentations are higher during the school year than during the summer months (Goldstein et al. 2005). To address this, GLM was used to control for trends-over-time. Finally, it was not possible to control for child, family or systemic factors (e.g. history of suicidal behaviour, stigma, distance from the ED), which might have impacted the decision to seek care at the local paediatric ED. Indeed, some youth might have presented to a general instead of a paediatric ED, and older youth might have sought adult instead of paediatric services. These ED presentations would therefore not have been captured in this study, but would still have led to an underestimation of presentations related to publicized teen suicides. Nevertheless, this study is the first to look at a help-seeking behaviour instead of subsequent completed suicides, providing a broader look and a better understanding of the influence of publicized suicides on community members.

\section{Conclusion}

This study confirmed that there has been an overall yearly increase in ED presentations, which corresponds with reported increases in paediatric $\mathrm{MH}$ presentations in Canadian and American EDs (Grupp-Phelan et al. 2007; Mahajan et al. 2009; Newton et al. 2009; Sills and Bland 2002). This study also suggests there was a short- and long-term increase in youth ED presentations following media coverage of youth suicides, but no significant clinical differences in presentation. However, it is still unknown whether the increase corresponded to 
higher awareness of $\mathrm{MH}$ issues. These findings may encourage more research on the potential positive role of responsible media coverage on MH awareness. Finally, as with Kurt Cobain's suicide, it might be important to have immediate outreach interventions from $\mathrm{MH}$ crisis centres following news of youth suicides. These outreach interventions might help to prevent an unwanted Werther effect by highlighting the existence of services available for youths in distress. Outreach interventions might also help relieve some of the sudden demands on already burdened EDs by informing and guiding youths and their families to the most appropriate services depending on needs and level of distress.

Correspondence may be directed to: Mario Cappelli, Ph.D., C.Psych., Children's Hospital of Eastern Ontario Research Institute, 401 Smyth Rd., Ottawa, Ontario, K1H 8L1.

\section{References}

Canadian Institute for Health Information (CIHI). 2006. International Statistical Classification of Diseases and Related Health Problems Canadian Version. 10th revision. Ottawa, ON: Author.

Cloutier, P., A. Kennedy, H. Maysenhoelder, E.J. Glennie, M. Cappelli and C. Gray. 2010."Pediatric Mental Health Concerns in the Emergency Department: Caregiver and Youth Perceptions and Expectations." Pediatric Emergency Care 26(2): 99-106. doi: 10.1097/PEC.0b013e3181cdcae1.

Edelsohn, G.A., L.E. Braitman, H. Rabinovich, P. Sheeves and A. Menlendez. 2003."Predictors of Urgency in a Pediatric Psychiatric Emergency Service." Journal of the American Academy of Child and Adolescent Psychiatry 42(10): 1197-202. doi: 10.1097/00004583-200310000-00010.

Goldstein, A.B., M.A.C. Silverman, S. Phillips and R. Lichenstein. 2005. "Mental Health Visits in a Pediatric Emergency Department and Their Relationship to the School Calendar." Pediatric Emergency Care 21(10): 653-57.

Gould, M.S. 2001. "Suicide and the Media." Annals of the New York Academy of Sciences 932: 200-24. doi: 10.1111/j.1749-6632.2001.tb05807.x.

Gould, M.S. 2003. "Media Contagion and Suicide Among the Young." American Behavioural Scientist 46(9): 1269-84. doi: 10.1177/0002764202250670.

Grupp-Phelan, J., J. Harman and K.J. Kelleher. 2007.“Trends in Mental Health and Chronic Condition Visits by Children Presenting for Care at U.S. Emergency Departments." Public Health Reports 122(1): 55-61.

Hodges, K. and J. Wotring. 2000. "Client Typology Based on Functioning Across Domains Using the CAFAS." The Journal of Behavioural Health Services and Research 27(3): 257-70.

Jobes, D.A., A.L. Berman, P.W. O'Carroll, S. Eastgard and S. Knickmeyer. 2006. “The Kurt Cobain Suicide Crisis: Perspectives from Research, Public Health, and the News Media." Suicide and Life-Threatening Behavior 26(3): 260-71. doi: 10.1111/j.1943-278X.1996.tb00611.x.

Kim, W.J., Y.J. Song, K. Namkoong, J.M. Kim, H.J. Yoon and E. Lee. 2013.“Does a Copycat Effect Exist in The Emergency Department?" International Journal of Psychiatry in Medicine 45(1): 59-72. doi: 10.2190/PM.45.1.e Lyons, J.S., L. Bisnaire, S. Greenham and J. Dods. 2006."The Child and Adolescent Needs and Strengths (CAN MH 3.0 Manual)." Retrieved February 10, 2013. <http://www.cebc4cw.org/assessment-tool/child-and-adolescentneeds-and-strengths-mental-health/>.

Mahajan, P., E. Alpern, J. Grupp-Phelan, J. Chamberlain, L. Dong, R. Holubkov et al. 2009.“Epidemiology of Psychiatric-Related Visits to Emergency Departments in a Multicenter Collaborative Research Pediatric Network." Pediatric Emergency Care 25(11): 730-35. doi: 10.1097/PEC.0b013e3181bec82f.

Nepon J., S. Fotti, L.Y. Katz and J. Sareen and Swampy Cree Suicide Prevention Team. 2008. “Media Guidelines for Reporting Suicide: A Review Article." Canadian Psychiatric Association Annual Meeting, Vancouver, BC. Newton M.S., S. Ali, D.W. Johnson, C. Haines, R.J. Rosychuk, R.A. Keaschuk et al. 2009. “A 4-Year Review of Pediatric Mental Health Emergencies in Alberta." Canadian Journal of Emergency Medicine 11(5): 447-54. 


\section{Media Coverage of Youth Suicides and Its Impact on Paediatric Mental Health Emergency Department Presentations}

Niederkrotenthaler T., M. Voracek, A. Herberth, B. Till, M. Strauss, E. Etzersdorfer et al. 2010."Role of Media Reports in Completed and Prevented Suicide: Werther v. Papageno Effects." The British Journal of Psychiatry 197(3): 234-43. doi: 10.1192/bjp.bp.109.074633.

Richardson, D.K., M. Paladini, T. Azarian, A. Baer, M. Rennick, and D. Weiss. 2011.“Increased Emergency Department Presentations for Head Trauma Following Media Coverage of a Fatal Epidural Hematoma". Emerging Health Threats Journal 4(51): 37-38. doi: 10.3134/ehtj.10.051.

Siask, M. and A. Värni. 2012. "Media Roles in Suicide Prevention: A Systematic Review." International Journal of Environmental Research and Public Health 9(2): 123-38. doi:10.3390/ijerph9010123.

Sills, M.R. and S.D. Bland. 2002." "Summary Statistics for Pediatric Psychiatric Visits to US Emergency Departments." Pediatrics 110(4): 1-5. doi: 10.1542/peds.110.4.e40.

Swanson, S.A. and I. Colman. 2013. "Association Between Exposure to Suicide and Suicidality Outcomes in Youth." Canadian Medical Association Journal 185(10): 870-77. doi:10.1503 /cmaj.121377.

Wright, A., P.D. McGorry, M.G. Harris, A.F. Jorm and K. Pennell. 2006. “Development and Evaluation of a Youth Mental Health Community Awareness Campaign - The Compass Strategy". BMC Public Health 6: 215. doi:10.1186/1471-2458-6-215.

Yang, A.C., S. Tsai, C. Yang, B. Shia, J. Fuh, S. Wang et al. 2013. “Suicide and Media Reporting: A Longitudinal and Spatial Analysis." Social Psychiatry and Psychiatric Epidemiology 48(3): 427-35. doi: 10.1007/s00127-0120562-1.

Yu, A.Y., N. Ata, K. Dong and A.S. Newton. 2010. “A Description of Emergency Care Received by Children and Youth with Mental Health Presentations for Alcohol and Other Drug Use in Two Alberta Emergency Departments." Journal of the Canadian Academy Child Adolescent Psychiatry 19(4): 290-96. 